\title{
Common water-plantain, a new host of Pseudomonas viridiflava in rice fields in Iran
}

\author{
Esmaeil Basavand $^{1} \cdot$ Pejman Khodaygan ${ }^{1}$
}

Received: 20 October 2019 / Accepted: 16 January 2020 / Published online: 3 February 2020

(C) Società Italiana di Patologia Vegetale (S.I.Pa.V.) 2020

Keywords Common water-plantain $\cdot$ Pseudomonas viridiflava $\cdot$ Phenotypic and molecular tests $\cdot$ Bacterial leaf spot

The common water-plantain (Alisma plantago-aquatica), is a common perennial weed in the rice fields of northern Iran. During the summer of 2017 , a leaf spot on common waterplantains was observed in the Mazandaran Province. The symptoms were small (50 to $100 \mathrm{~mm}^{2}$ ), round, and dark brown spots, which expanded with time, in a final stage leaves became completely necrotic and dried out. From these symptoms a green fluorescent bacterium was consistently isolated. Isolation and subsequent purification and biochemical profiling of causal organism were performed according to methods described by Borkar (2017). Upon isolation bacterial colonies on NSA medium were mucoid, circular, and cream-colored, $2 \mathrm{~mm}$ in diameter after $48 \mathrm{~h}$ growth. Ten isolates were negative in tests for oxidase, production of levan, hydrolysis of tween 80 , urease, 3'-ketolactose, gas from glucose, phenylalanine deaminase, lecithinase, indole, arginine dihydrolase, $\mathrm{H}_{2} \mathrm{~S}$ from peptone, thiosulfate and cysteine but were fluorescent on King's B medium and were positive in tests for catalase, potato soft rot, nitrate reduction, $\mathrm{RSS}, \mathrm{NaCl} 4$ and $6 \%$ tolerance, tyrosinase activity, hydrolysis of casein, starch, esculin, gelatine, and arbutin. Litmus milk was turned alkaline and digested by isolates. Tested isolates used L-glutamine, Dgalactose, D-tartrate, proline, L-tyrosine, succinic acid, malonate, D-xylulose, fructose, maltose, sucrose, L-valine, L-arabinose, fumarate, melibiose, glucose, mannitol, but not L-serine, L-tartrate, D-raffinose, D-lactose, D-cellobiose, sorbose, L-ornithine, L-arginine as carbon source for growth. In all of the tests, the type strain of Pseudomonas viridiflava (ATCC 13223) was used as a positive control and the isolates in this study were deposited in the Culture Collection of

Pejman Khodaygan

pkhodaygan@vru.ac.ir

1 Department of Plant Pathology, Vali-e-Asr University of Rafsanjan, Rafsanjan, Iran
Microorganisms in Vali-E-Asr University of Rafsanjan, Iran, under the numbers (ten isolates) VRU 1249 to VRU 1259. A pathogenicity test performed under greenhouse conditions by inoculation of a bacterial suspension of approximately $1 \times$ $10^{6} \mathrm{CFU} / \mathrm{ml}$ into mature leaves of common water-plantain plants yielded similar symptoms as observed in nature 10 days after inoculation. From these symptoms the pathogen was reisolated and pathogenicity confirmed by Koch's postulates. For final identification, the partial 16S rRNA and rpoD genes from one representative isolate were amplified and sequenced (Rico et al. 2003; Weisburg et al. 1991), and sequences compared using the Blast software available at the NCBI database with other sequences in GenBank. The sequences of this isolate showed 100\% similarity (rpoD: KY764288.1) and 99\% (16S rRNA: MH793501) with those of the mentioned $P$. viridiflava strains. To our knowledge this is the first report of $P$. viridiflava, as a bacterial pathogen of common waterplantain in Iran.

Acknowledgments This research was supported by Vice Chancellor of Research and Technology grant (AGR95PP5938) at the Vali-E-Asr University of Rafsanjan, Iran.

\section{References}

Borkar SG (2017) Laboratory techniques in plant bacteriology. CRC Press, New York, 499 pp

Rico A, López R, Asensio C, Aizpún MT, Asensio S, Manzanera MC, Murillo J (2003) Nontoxigenic strains of Pseudomonas syringae pv. phaseolicola are a main cause of halo blight of beans in Spain and escape current detection methods. Phytopathology 93:1553-1559

Weisburg WG, Barns SM, Pelletier DA, Lane DJ (1991) 16S ribosomal DNA amplification for phylogenetic study. J Bac 173:697-703

Publisher's note Springer Nature remains neutral with regard to jurisdictional claims in published maps and institutional affiliations. 